\title{
Effects of arachidonic acid intake on inflammatory reactions in dextran sodium sulphate-induced colitis in rats
}

\author{
Yukiko Naito ${ }^{1,2 *}, \mathrm{Xu} \mathrm{Ji}^{1,3}$, Shigehiro Tachibana ${ }^{4}$, Satoko Aoki ${ }^{4}$, Mami Furuya ${ }^{4}$, Yoshiyuki Tazura ${ }^{4}$, \\ Daisuke Miyazawa $^{5}$, Akiko Harauma ${ }^{6}$, Toru Moriguchi ${ }^{6}$, Tomoko Nagata ${ }^{4}$, Naoharu Iwai ${ }^{1}$ and \\ Naoki Ohara ${ }^{5}$ \\ ${ }^{1}$ Department of Genomic Medicine, National Cerebral and Cardiovascular Center, Suita, Osaka 565-8565, Japan \\ ${ }^{2}$ Department of Health Science, School of Allied Health Sciences and Graduate School of Medical Sciences, Kitasato University, \\ Sagamihara, Kanagawa 252-0373, Japan \\ ${ }^{3}$ State Key Laboratory of Phytochemistry and Plant Resources in West China, Kunming Institute of Botany, Chinese Academy \\ of Sciences, Kunming, Yunnan 650201, China \\ ${ }^{4}$ Hatano Research Institute, Food and Drug Safety Center, Hadano, Kanagawa 257-8523, Japan \\ ${ }^{5}$ College of Pharmacy, Kinjo Gakuin University, Nagoya, Aichi 463-8521, Japan \\ ${ }^{6}$ Department of Food and Life Science, School of Life and Environmental Science, Azabu University, Sagamihara, Kanagawa \\ 252-0206, Japan
}

(Submitted 9 October 2014 - Final revision received 22 May 2015 - Accepted 29 May 2015 - First published online 3 August 2015)

\section{Abstract}

The aim of this study was to investigate the effects of the administration of oral arachidonic acid (AA) in rats with or without dextran sulphate sodium (DSS)-induced inflammatory bowel disease. Male Wistar rats were administered AA at 0, 5, 35 or $240 \mathrm{mg} / \mathrm{kg}$ daily by gavage for 8 weeks. Inflammatory bowel disease was induced by replacing drinking water with $3 \%$ DSS solution during the last $7 \mathrm{~d}$ of the AA dosing period. These animals passed loose stools, diarrhoea and red-stained faeces. Cyclo-oxygenase- 2 concentration and myeloperoxidase activity in the colonic tissue were significantly increased in the animals given AA at $240 \mathrm{mg} / \mathrm{kg}$ compared with the animals given AA at $0 \mathrm{mg} / \mathrm{kg}$. Thromboxane $B_{2}$ concentration in the medium of cultured colonic mucosae isolated from these groups was found to be dose-dependently increased by AA, and the increase was significant at 35 and $240 \mathrm{mg} / \mathrm{kg}$. Leukotriene $\mathrm{B}_{4}$ concentration was also significantly increased and saturated at $5 \mathrm{mg} / \mathrm{kg}$. In addition, AA at $240 \mathrm{mg} / \mathrm{kg}$ promoted DSS-induced colonic mucosal oedema with macrophage infiltration. In contrast, administration of AA for 8 weeks, even at $240 \mathrm{mg} / \mathrm{kg}$, showed no effects on the normal rats. These results suggest that in rats with bowel disease AA metabolism is affected by oral AA, even at $5 \mathrm{mg} / \mathrm{kg}$ per $\mathrm{d}$, and that excessive AA may aggravate inflammation, whereas AA shows no effects in rats without inflammatory bowel disease.

Key words: Arachidonic acid: Colitis: Dextran sodium sulphate: Supplementation

Arachidonic acid (AA, $20: 4 n-6$ ) is one of the $n$-6 PUFA present in the cell membrane and is essential for maintaining cell functions. AA has been reported to play a crucial role in the brain functions of both aged animals and elderly people ${ }^{(1-6)}$. Moreover, as AA is also essential for perinatal and neonatal development ${ }^{(7-9)}$, AA is added to infant formula ${ }^{(10)}$.

However, it should be noted that AA serves as a precursor to pro- and anti-inflammatory eicosanoids. Excessive AA consumption can occur as long as food supplements containing AA are available on the market and consumers include, inevitably, persons who are subject to inflammatory diseases, manifested or not. Thus, it is important to evaluate the influence of AA on an underlying inflammation. In this study, whether or not dextran sulphate sodium (DSS)-induced colitis was affected by AA intake was examined in rats. The reason DSS-induced colitis was chosen as the inflammation model was that the model is structurally and clinically similar to human ulcerative colitis ${ }^{(11,12)}$ and has been used in previous studies dealing with AA effects on experimental inflammation ${ }^{(13,14)}$.

In the present study, rats were orally administered AA at doses of $0,5,35$ and $240 \mathrm{mg} / \mathrm{kg}$ per d for 8 weeks; $5 \mathrm{mg} / \mathrm{kg}$ per $\mathrm{d}$ corresponded approximately to the doses used in previous human studies ${ }^{(5,15)}$, and the highest $-240 \mathrm{mg} / \mathrm{kg}$ per $\mathrm{d}$ - was set to examine the possible toxicity of AA. Thus, in parallel with the

Abbreviations: 6-keto $\mathrm{PGF}_{1 \alpha}$, 6-keto prostaglandin $\mathrm{F}_{1 \alpha}$; AA, arachidonic acid; COX-2, cyclo-oxygenase-2; DSS, dextran sulphate sodium; LTB 4 , leukotriene $\mathrm{B}_{4}$; $\mathrm{MPO}$, myeloperoxidase; $\mathrm{PGE}_{2}$, prostaglandin $\mathrm{E}_{2} ; \mathrm{TXB}_{2}$, thromboxane $\mathrm{B}_{2}$.

* Corresponding author: Dr Y. Naito, fax +81 42778 8073, email naitoy@kitasato-u.ac.jp 
rats with DSS-induced colitis, those without DSS-induced colitis were administered $\mathrm{AA}$ at 0 and $240 \mathrm{mg} / \mathrm{kg}$ per $\mathrm{d}$ for 8 weeks and were observed for toxicological signs.

\section{Methods}

Fatty acid analysis of arachidonic acid-rich dietary oil and vehicle oil

AA-rich dietary oil and the vehicle oil $(n 3)$ were diluted with a methanol-hexane vehicle containing butylhydroxytoluene as an antioxidant and docosatrienoic acid methyl ester (C22 : 3n-3 methyl ester) as an internal standard. After adding acetyl chloride, the mixture was heated at $100^{\circ} \mathrm{C}$ for $60 \mathrm{~min}$ for extraction and methylation of lipids. The samples were shaken with potassium carbonate solution. Fatty acid methyl esters in the hexane layer were determined using Agilent 7890A gas chromatograph (Agilent Technologies) with a split injector (Agilent 7693 automatic liquid sampler; Agilent Technologies), and were detected using a flame ionisation detector (Agilent Technologies). The GC column used was a DB-FFAP $15 \mathrm{~m} \times 0.10 \mathrm{~mm}$ i.d. with $0.10 \mu \mathrm{m}$ film thickness (J\&W Scientific from Agilent Technologies). The oven temperature programme was initiated at $150^{\circ} \mathrm{C}$ with a 0.25 -min hold, and then ramped up at $35^{\circ} \mathrm{C} / \mathrm{min}$ to $200^{\circ} \mathrm{C}$, then at $8^{\circ} \mathrm{C} / \mathrm{min}$ to $225^{\circ} \mathrm{C}$ with a $3 \cdot 2-\mathrm{min}$ hold and finally ramped up at $80^{\circ} \mathrm{C} / \mathrm{min}$ to $248^{\circ} \mathrm{C}$ with a $14.7-\mathrm{min}$ hold. The detector and injector temperatures were both set at $250^{\circ} \mathrm{C}$.

\section{Animals, dosage of arachidonic acid and dextran sulphate} sodium treatment

Male Wistar rats (Japan SLC), 4 weeks old, were acclimatised for 1 week and housed individually in metal cages with mesh bottoms. The temperature and humidity of the breeding room were maintained at $21-25^{\circ} \mathrm{C}$ and $40 \cdot 0-75 \cdot 0 \%$, respectively, with ventilation at 15 changes/ $\mathrm{h}$ and a $12-\mathrm{h}$ light/dark cycle. The rats were allowed free access to a standard diet for rodents (CE-2; CLEA Japan) and tap water.

AA-rich dietary oil (>40\% (w/w) AA; Cabio Bioengineering) was mixed with vehicle oil, a mixture of lard:rapeseed oil: soyabean oil $=2: 1: 1$ (Ueda Oils and Fats), and test oils containing AA at $0,8 \cdot 3,58 \cdot 3$ and $400 \mathrm{mg} / \mathrm{ml}$ were prepared. Deficiency of $n$ - 3 PUFA was avoided by using CE- 2 as the basal diet, as CE- 2 contains a sufficient quantity of $n-3$ PUFA.

A total of sixty rats were randomly divided into six groups of ten rats each based on body weight. Four groups were given $0.6 \mathrm{ml} / \mathrm{kg}$ of vehicle oil or test oils, yielding dosages of AA at 0 , 5,35 and $240 \mathrm{mg} / \mathrm{kg}$. The oils were administered once daily by gavage for 8 weeks. Dose levels were determined based on previous studies in humans ${ }^{(5,15)}$; the lowest dose, $5 \mathrm{mg} / \mathrm{kg}$ per $\mathrm{d}$, was comparable with the dose, $240 \mathrm{mg} / \mathrm{d}$ per body, in those studies. The highest dose in the present study was approximately fifty times the lowest one - that is, about fifty times as high as that in a previous human study ${ }^{(15)}$. The drinking water was replaced with water containing 3\% DSS (Wako Pure Chemical Industries) for the last $7 \mathrm{~d}$ in the 8 th week of the AA administration period (i.e. the $0,5,35$ and $240 \mathrm{mg} / \mathrm{kg}$ AA with
DSS groups) ${ }^{(11,12)}$. The other two groups were given $0.6 \mathrm{ml} / \mathrm{kg}$ of vehicle oil or AA-rich oil mixtures, yielding dosages of AA at 0 and $240 \mathrm{mg} / \mathrm{kg}$ per $\mathrm{d}$ without DSS treatment (i.e. the 0 and $240 \mathrm{mg} / \mathrm{kg}$ AA without DSS groups).

The protocol for the present study was approved by the Committee for Ethical Usage of Experimental Animals at Hatano Research Institute, Food and Drug Safety Center (authorisation no. 2100030A).

\section{Gross observation, body weight, food intake and water intake}

The general condition of the animals was observed daily. Faecal properties were classified into the following five categories: normal, loose, reddish brown-stained, red-stained and diarrhoea. Body weight and food intake were measured once a week. Daily water intake was measured for the last $7 \mathrm{~d}$.

\section{Haematological observation}

After the 8-week AA administration period, the animals were fasted for $18 \mathrm{~h}$. Under anaesthesia with pentobarbital, blood was collected from the abdominal vein using EDTA-2K as an anticoagulant. Densities of erythrocytes, leucocytes and platelets were measured; $\mathrm{Hb}$, mean corpuscular volume (MCV), mean corpuscular haemoglobin and mean corpuscular haemoglobin concentration (MCHC) were determined; and differential leucocyte count, reticulocyte ratio and haematocrit (HCT) were calculated using an automated haematology analyser (XT-2000iV; Sysmex).

\section{Biochemical analysis in plasma}

Plasma was obtained from the blood samples taken from the abdominal vein using heparin as an anticoagulant, and the following parameters were determined using an auto-analyser (JCA-BM6010; JEOL): the concentrations of total protein, albumin, glucose, total cholesterol, TAG, phospholipids, NEFA, total bilirubin, blood urea nitrogen, creatinine, calcium ions and inorganic phosphorus; the albumin:globulin ratio; and the activities of $\gamma$-glutamyl transpeptidase, alkaline phosphatase, aspartate aminotransferase and alanine aminotransferase. The concentrations of sodium, potassium and chloride ions were measured using an electrolyte auto-analyser (EA05; A\&T).

\section{Measurement of plasma fatty acids}

Plasma lipids were extracted using a chloroform/methanol mixture according to the method of Bligh et al. ${ }^{(16)}$. Heptadecanoic acid ( $10 \mu \mathrm{l}$; Sigma) was added as an internal standard. Fatty acids yielded in the extract were heated and esterified in methanol containing $5 \% \mathrm{HCl}$ at $100^{\circ} \mathrm{C}$ for $1 \mathrm{~h}$ (Tokyo Kasei). Subsequently, fatty acid composition was determined by capillary column (0.25 mm diameter, $30 \mathrm{~m}$ length; J\&W DB-225; Agilent Technologies) GLC (GC-18A; Shimadzu). The column temperature was held at $120^{\circ} \mathrm{C}$ for $2 \mathrm{~min}$, then ramped up to $200^{\circ} \mathrm{C}$ at a rate of $5^{\circ} \mathrm{C} / \mathrm{min}$, then to $208^{\circ} \mathrm{C}$ at a rate of $3^{\circ} \mathrm{C} / \mathrm{min}$ and held at $208^{\circ} \mathrm{C}$ for $45 \mathrm{~min}$. The injector and detector temperatures were both set at $250^{\circ} \mathrm{C}$. 


\section{Pathological examination}

Following the collection of blood samples, the animals were killed by exsanguination and were necropsied

The length and weight of the colon isolated from each animal were measured, and relative weight to length was calculated. Four pieces of the large intestine were cut in the following order, starting from the end closest to the anus, with the following lengths: approximately 3,1, 4 and $1 \mathrm{~cm}$. The second section was used for pathological examination, and the first and the third sections were used for eicosanoid analysis and ulcerated area measurement, respectively. The fourth section was used for measuring myeloperoxidase (MPO) activity and cyclo-oxygenase-2 (COX-2) concentration. The third section of the colon was opened along the long axis and placed in $3 \%$ acetic acid solution for $5 \mathrm{~min}$. After being rinsed in water, the colon was stained with $1 \%$ Alcian blue solution for $20 \mathrm{~min}$, followed by immersion in $3 \%$ acetic acid solution. Subsequently, the tissues were photographed (COOLPIX5700; Nikon). The total area of the areas stained dark blue in the mucosa were measured with Image J Software (Version 1.44p; NIH), and the ratio of stained areas to that of the colonic mucosa observed was calculated.

For evaluating macrophage infiltration, the sections of the caecum and colon in the 0 and $240 \mathrm{mg} / \mathrm{kg}$ AA with DSS groups were de-paraffinised and incubated with a primary antibody to CD68 (1:500; ABD) at $4^{\circ} \mathrm{C}$ overnight and, subsequently, with a secondary antibody (Simplestain MAX-PO; Nichirei Biosciences) for $20 \mathrm{~min}$ at room temperature. These preparations were stained with 3,3-diaminobenzidene (DAB; Dojindo Laboratories), and DAB-positive cells in five randomly selected microscopic fields were counted to calculate the density of DAB-positive cells.

The brain, heart, liver, kidneys, spleen, adrenals and testes were weighed, and the relative organ-to-body weights were calculated for individual animals. These organs, as well as the pituitary gland, aorta, thyroid gland (with parathyroids), thymus, lungs (with bronchi), stomach, duodenum, caecum, jejunum, ileum, colon, submandibular lymph nodes, prostate and urinary bladder, were fixed in $0 \cdot 1 \mathrm{~m}$-phosphate-buffered $10 \%$ formalin solution. The testes and the epididymides were fixed in Bouin's solution. After paraffin embedding, the specimens were sectioned at a thickness of $4 \mu \mathrm{m}$, stained with haematoxylineosin and examined under a microscope.

\section{Myeloperoxidase activity measurement}

Part of the fourth colonic section was homogenised in phosphate buffer, and aliquots were centrifuged at $13000 \boldsymbol{g}$ for $10 \mathrm{~min}$ at $4{ }^{\circ} \mathrm{C}$. The resulting pellets were re-suspended, and MPO activity was determined as hypochlorous acid production using a commercial kit (Myeloperoxidase Activity Assay kit; BioVision) following the manufacturer's instructions.

\section{Cyclo-oxygenase-2 concentration measurement}

The remaining fourth section of the colonic tissue was homogenised in a lysis buffer (IBLysis-1; Immuno-Biological Laboratories). The homogenates were maintained at $4^{\circ} \mathrm{C}$ for $4 \mathrm{~h}$, followed by centrifugation at $8000 \mathrm{~g}$ for $10 \mathrm{~min}$ at $4^{\circ} \mathrm{C}$ and the supernatants were obtained. COX-2 levels in the supernatants were assayed using a commercial ELISA kit (Rat COX-2 assay kit; Immuno-Biological Laboratories) following the manufacturer's instructions. COX-2 levels were expressed as $\mathrm{ng} / \mathrm{mg}$ protein. Protein concentrations in the sample homogenates were determined using a protein assay kit (BCA protein assay kit; Takara).

\section{Determination of eicosanoid concentrations in culture media of the colonic mucosa}

Isolated colonic mucosa, approximately $30 \mathrm{mg}$ from each animal, was incubated in RPMI164 medium containing 10\% fetal bovine serum, $2 \mathrm{~mm}$ L-glutamine, $100 \mathrm{U} / \mathrm{ml}$ penicillin and $100 \mu \mathrm{g} / \mathrm{ml}$ streptomycin (Life Technologies) for $24 \mathrm{~h}$ at $37^{\circ} \mathrm{C}$ in $5 \% \mathrm{CO}_{2}$. After incubation, culture media was collected and stored at $-80^{\circ} \mathrm{C}$ until use. Thromboxane $\mathrm{B}_{2}\left(\mathrm{TXB}_{2}\right)$, 6-keto prostaglandin $\mathrm{F}_{1 \alpha}\left(6\right.$-keto $\left.\mathrm{PGF}_{1 \alpha}\right)$, prostaglandin $\mathrm{E}_{2}\left(\mathrm{PGE}_{2}\right)$ and leukotriene $\mathrm{B}_{4}\left(\mathrm{LTB}_{4}\right)$ were determined using commercially available EIA kits (Cayman Chemical). Concentrations of these eicosanoids were expressed as $\mathrm{pg} / \mathrm{mg}$ protein. Protein concentrations in the samples were determined using a protein assay kit (BCA protein assay reagent kit; Takara).

\section{Statistical analysis}

The results of this study are presented as the mean values and their standard errors. Equality of variance was tested with Bartlett's test, and differences between group mean values were evaluated by Dunnett's test. When variance of values obtained was not equal, Kruskal-Wallis one-way ANOVA by ranks was used followed by Dunn's test. A two-tailed unpaired $t$ test was used when two group mean values were compared between $0 \mathrm{mg} / \mathrm{kg}$ AA with and without DSS groups, 0 and $240 \mathrm{mg} / \mathrm{kg} \mathrm{AA}$ without DSS groups and 0 and $240 \mathrm{mg} / \mathrm{kg}$ AA with DSS groups. Graded data in the pathological examinations were evaluated by Mann-Whitney's $U$ test. Dose-dependency was confirmed by regression analysis. Differences were considered statistically significant when the $P$ value was $<0.05$.

\section{Results}

Fatty acid composition of arachidonic acid-rich dietary oil and vehicle oil

Results are shown in Table 1. AA content in AA-rich dietary oil and the vehicle oil were approximately 40.4 and $0.05 \%(\mathrm{w} / \mathrm{w})$, respectively.

\section{General condition, body weight and food and water intake}

At the end of the 8th week, anaemia was observed in animals in the DSS-treated groups: six, nine, six and nine animals in the $0,5,35$ and $240 \mathrm{mg} / \mathrm{kg}$ AA with DSS groups, respectively. The incidence of anaemia was not different between the groups. On the 3rd day, and after, during the DSS treatment period, loose stools, diarrhoea and red-stained faeces were observed in each group (online Supplementary Table S1). Although the onset of these symptoms tended to be earlier in the $240 \mathrm{mg} / \mathrm{kg}$ AA group 
Table 1. Fatty acid compositions of arachidonic acid (AA)-rich dietary oil and vehicle oil (\% total fatty acids)

(Mean values with their standard errors; $n 3$ )

\begin{tabular}{|c|c|c|c|c|}
\hline \multirow[b]{2}{*}{ Fatty acid } & \multicolumn{2}{|c|}{ AA-rich dietary oil } & \multicolumn{2}{|c|}{ Vehicle oil } \\
\hline & Mean & SE & Mean & SE \\
\hline $12: 0$ & \multicolumn{2}{|c|}{ ND } & 0.06 & 0.001 \\
\hline $14: 0$ & 0.40 & 0.01 & 0.91 & 0.003 \\
\hline $16: 0$ & 6.95 & 0.01 & $16 \cdot 12$ & 0.02 \\
\hline $18: 0$ & 5.91 & 0.02 & 8.74 & 0.01 \\
\hline $20: 0$ & 0.81 & 0.004 & 0.34 & 0.01 \\
\hline $22: 0$ & $3 \cdot 21$ & 0.01 & 0.22 & 0.003 \\
\hline $23: 0$ & $0 \cdot 10$ & 0.01 & \multicolumn{2}{|c|}{ ND } \\
\hline $24: 0$ & 9.51 & 0.01 & 0.09 & 0.01 \\
\hline $14: 1$ & \multicolumn{2}{|c|}{ ND } & 0.14 & 0.001 \\
\hline $16: 1 n-7$ & 0.22 & 0.001 & 1.35 & 0.01 \\
\hline $18: 1 n-9$ & $5 \cdot 31$ & 0.003 & 39.98 & 0.04 \\
\hline $18: 1 n-7$ & 0.27 & 0.004 & 2.54 & 0.01 \\
\hline $20: 1 n-9$ & 0.22 & 0.001 & 0.79 & 0.04 \\
\hline $22: 1 n-9$ & 0.07 & 0.01 & \multicolumn{2}{|c|}{ ND } \\
\hline $24: 1$ & 0.37 & 0.01 & \multicolumn{2}{|c|}{ ND } \\
\hline $18: 2 n-6$ & $9 \cdot 38$ & 0.01 & $22 \cdot 26$ & 0.03 \\
\hline $18: 3 n-6$ & 2.40 & 0.004 & 0.03 & 0.01 \\
\hline $20: 2 n-6$ & 0.47 & 0.002 & 0.20 & 0.01 \\
\hline $20: 3 n-6$ & 3.85 & 0.01 & \multicolumn{2}{|c|}{ ND } \\
\hline $20: 4 n-6$ & $45 \cdot 11$ & 0.04 & 0.05 & 0.002 \\
\hline $22: 4 n-6$ & 0.31 & 0.004 & \multicolumn{2}{|c|}{ ND } \\
\hline $18: 3 n-3$ & 0.06 & 0.003 & 3.84 & 0.01 \\
\hline $20: 5 n-3$ & 0.52 & 0.002 & $0 \cdot 10$ & 0.001 \\
\hline $22: 5 n-3$ & \multirow{2}{*}{\multicolumn{2}{|c|}{$\begin{array}{l}\text { ND } \\
\text { ND }\end{array}$}} & \multirow{2}{*}{\multicolumn{2}{|c|}{$\begin{array}{l}\text { ND } \\
\text { ND }\end{array}$}} \\
\hline $22: 6 n-3$ & & & & \\
\hline AA content $(\mathrm{mg} / \mu \mathrm{l})$ & 37.5 & 0.2 & 0.043 & 0.002 \\
\hline AA content $(\mathrm{mg} / 100 \mathrm{mg})$ & 40.4 & 0.2 & 0.047 & 0.002 \\
\hline
\end{tabular}

ND, not detected.

than in the other groups, the grades of symptoms were not different between the groups. In the groups without DSS treatment, there were no abnormal findings in any of the animals for 8 weeks.

Up to the 7th week of AA administration, body weight increased in all the animals, and there were no significant differences between the groups. In each group treated with DSS, the mean body weight at the last day of observation (day 56) tended to be lower than that on day 50 . However, in the groups without DSS treatment, body weight increased until the last day of the AA administration period (data not shown). During the AA administration period, food intakes in all the groups tested were similar. Daily intake of the 3\% DSS solution was not different between the groups (online Supplementary Tables S2 and S3).

\section{Haematology and blood biochemistry}

The results are shown in Table 2 . In the differential leucocyte counts, neutrophils were decreased and lymphocytes were increased in the $240 \mathrm{mg} / \mathrm{kg}$ AA with DSS group compared with the $0 \mathrm{mg} / \mathrm{kg}$ AA with DSS group $(P<0 \cdot 05)$. Reticulocytes in the $0 \mathrm{mg} /$ $\mathrm{kg}$ AA with DSS group were higher than in the $0 \mathrm{mg} / \mathrm{kg}$ AA without DSS group $(P<0 \cdot 001)$. There were no differences in any other haematological parameters between the $0,5,35$ and $240 \mathrm{mg} / \mathrm{kg} \mathrm{AA}$ with DSS groups. In contrast, significant differences were found between the groups with and without DSS treatment. RBC count, $\mathrm{HCT}, \mathrm{Hb}$ and $\mathrm{MCHC}$ in the $0 \mathrm{mg} / \mathrm{kg}$ AA with DSS group were lower compared with the $0 \mathrm{mg} / \mathrm{kg}$ AA without DSS group
$(P<0 \cdot 001)$. Leucocyte count and MCV were increased in the $0 \mathrm{mg} /$ $\mathrm{kg}$ AA with DSS group compared with the $0 \mathrm{mg} / \mathrm{kg}$ AA without DSS group $(P<0 \cdot 001)$.

There were no significant differences in the blood biochemistry between the four groups treated with DSS (Table 3). In the $0 \mathrm{mg} / \mathrm{kg}$ AA with DSS group, the total protein, albumin and glucose levels as well as the albumin:globulin ratio were lower, and the total cholesterol, blood urea nitrogen and potassium levels were higher, compared with the $0 \mathrm{mg} / \mathrm{kg}$ AA without DSS group.

\section{Plasma fatty acids}

In the DSS-treated groups, plasma AA levels in the $240 \mathrm{mg} / \mathrm{kg}$ AA group were higher compared with the $0 \mathrm{mg} / \mathrm{kg}$ AA group. $\mathrm{EPA}: \mathrm{AA}$ and $(\mathrm{EPA}+\mathrm{DHA}): \mathrm{AA}$ ratios between the DSS-treated groups were not different. The EPA:AA ratio in the $240 \mathrm{mg} / \mathrm{kg}$ AA group tended to be lower than that in the $0 \mathrm{mg} / \mathrm{kg}$ AA group (Fig. 1). In the groups without DSS treatment, AA level was higher, and EPA:AA and (EPA + DHA):AA ratios were lower in the $240 \mathrm{mg} / \mathrm{kg}$ AA group, compared with the $0 \mathrm{mg} / \mathrm{kg}$ AA group. The EPA:AA ratio in the $0 \mathrm{mg} / \mathrm{kg}$ AA without DSS group was higher compared with the $0 \mathrm{mg} / \mathrm{kg}$ AA with DSS group.

\section{Organ weights and macroscopic findings}

There were no differences in relative organ weights between the six groups (data not shown). 
Table 2. Haematology in the rats orally administered arachidonic acid (AA) for 8 weeks (Mean values with their standard errors; ten animals)

\begin{tabular}{|c|c|c|c|c|c|c|c|c|c|c|c|c|c|c|}
\hline \multirow[b]{2}{*}{ Group } & \multicolumn{2}{|c|}{ Erythrocytes $\left(\times 10^{4} / \mu \mathrm{l}\right)$} & \multicolumn{2}{|c|}{ HCT (\%) } & \multicolumn{2}{|c|}{$\mathrm{Hb}(\mathrm{g} / \mathrm{l})$} & \multicolumn{2}{|c|}{ RET (\%) } & \multicolumn{2}{|c|}{ MCV (fl) } & \multicolumn{2}{|c|}{$\mathrm{MCH}(\mathrm{pg})$} & \multicolumn{2}{|c|}{$\mathrm{MCHC}(\mathrm{g} / \mathrm{l})$} \\
\hline & Mean & SE & Mean & SE & Mean & SE & Mean & SE & Mean & $\mathrm{SE}$ & Mean & SE & Mean & $\mathrm{SE}$ \\
\hline $0 \mathrm{mg} / \mathrm{kg}$ AA with DSS & $476 \cdot 7^{\star \star \star \star}$ & 63.5 & $26 \cdot 3^{\star \star \star \star}$ & 2.7 & $81^{\star \star \star \star}$ & 1 & $16 \cdot 9^{\star \star \star \star}$ & 2.5 & $57 \cdot 7^{\star \star \star}$ & $2 \cdot 3$ & $17 \cdot 2$ & 0.3 & $301^{\star \star \star \star}$ & 9 \\
\hline $5 \mathrm{mg} / \mathrm{kg}$ AA with DSS & 317.9 & 24.4 & $20 \cdot 6$ & 0.9 & 56 & 4 & 29.7 & 3.6 & $66 \cdot 0$ & $2 \cdot 3$ & $17 \cdot 7$ & 0.3 & 269 & 7 \\
\hline $35 \mathrm{mg} / \mathrm{kg}$ AA with DSS & $486 \cdot 2$ & 70.7 & $26 \cdot 8$ & 2.8 & 82 & 11 & $21 \cdot 1$ & $5 \cdot 6$ & $59 \cdot 0$ & 3.5 & $17 \cdot 2$ & 0.3 & 297 & 11 \\
\hline $240 \mathrm{mg} / \mathrm{kg} \mathrm{AA}$ with DSS & $362 \cdot 3$ & $61 \cdot 4$ & $21 \cdot 7$ & $2 \cdot 3$ & 62 & 10 & $24 \cdot 0$ & $3 \cdot 3$ & $63 \cdot 0$ & $2 \cdot 5$ & $17 \cdot 5$ & 0.3 & 281 & 9 \\
\hline $0 \mathrm{mg} / \mathrm{kg} \mathrm{AA}$ without DSS & 936.7 & $10 \cdot 1$ & $44 \cdot 3$ & 0.2 & 155 & 1 & 3.7 & 0.1 & $47 \cdot 3$ & 0.4 & $16 \cdot 6$ & 0.1 & 351 & 2 \\
\hline \multirow[t]{2}{*}{$240 \mathrm{mg} / \mathrm{kg}$ AA without DSS } & $912 \cdot 4$ & $11 \cdot 1$ & 43.6 & 0.5 & 152 & 2 & 3.8 & 0.1 & $47 \cdot 8$ & 0.3 & $16 \cdot 7$ & 0.1 & 348 & 2 \\
\hline & \multicolumn{2}{|c|}{ Leucocytes $\left(\times 10^{2} / \mu l\right)$} & \multicolumn{2}{|c|}{ NEUT (\%) } & \multicolumn{2}{|c|}{ LYMPH (\%) } & \multicolumn{2}{|c|}{ MONO (\%) } & \multicolumn{2}{|c|}{ EOS (\%) } & \multicolumn{2}{|c|}{ BASO (\%) } & \multicolumn{2}{|c|}{$\operatorname{PLT}\left(\times 10^{4} / \mu \mathrm{l}\right)$} \\
\hline Group & Mean & $\mathrm{SE}$ & Mean & SE & Mean & SE & Mean & SE & Mean & $\mathrm{SE}$ & Mean & SE & Mean & SE \\
\hline $0 \mathrm{mg} / \mathrm{kg}$ AA with DSS & $122 \cdot 1^{\star \star \star \star}$ & 7.6 & 21.3 & 1.6 & $75 \cdot 4$ & 1.7 & $2 \cdot 7^{\star}$ & 0.2 & $0.5^{\star \star \star \star}$ & 0.1 & $0 \cdot 1^{\star *}$ & 0.0 & $76 \cdot 6$ & 2.7 \\
\hline $5 \mathrm{mg} / \mathrm{kg}$ AA with DSS & 143.9 & $9 \cdot 1$ & $17 \cdot 0$ & 1.9 & 78.9 & 1.8 & 3.6 & 0.5 & 0.3 & 0.0 & 0.1 & 0.0 & 82.6 & 4.8 \\
\hline $35 \mathrm{mg} / \mathrm{kg}$ AA with DSS & $147 \cdot 7$ & $10 \cdot 0$ & $20 \cdot 2$ & 1.7 & $76 \cdot 2$ & 1.7 & 3.2 & 0.4 & 0.4 & 0.1 & 0.1 & 0.0 & 79.0 & 4.1 \\
\hline $240 \mathrm{mg} / \mathrm{kg}$ AA with DSS & $124 \cdot 3$ & $12 \cdot 4$ & $14.6 \dagger$ & $1 \cdot 3$ & $82.5 \dagger$ & $1 \cdot 2$ & $2 \cdot 4$ & 0.3 & 0.3 & 0.1 & 0.1 & 0.0 & 80.5 & 4.7 \\
\hline $0 \mathrm{mg} / \mathrm{kg} \mathrm{AA}$ without DSS & 61.9 & 3.9 & 21.4 & 1.2 & $75 \cdot 5$ & 1.2 & 2.0 & 0.1 & 1.1 & 0.1 & 0.0 & 0.0 & $76 \cdot 6$ & $2 \cdot 0$ \\
\hline $240 \mathrm{mg} / \mathrm{kg}$ AA without DSS & 58.8 & $2 \cdot 7$ & $20 \cdot 6$ & 1.5 & $76 \cdot 3$ & 1.6 & $2 \cdot 1$ & 0.1 & 1.0 & 0.1 & 0.0 & 0.0 & $70 \cdot 2$ & 1.8 \\
\hline
\end{tabular}

HCT, haematocrit; RET, reticulocytes; MCV, mean corpuscular volume; MCH, mean corpuscular haemoglobin; MCHC, mean corpuscular haemoglobin concentration; DSS, dextran sodium sulphate; NEUT, neutrophils; LYMPH, lymphocytes; MONO, monocytes; EOS, eosinophils; BASO, basophils; PLT, platelets.

Mean value was significantly different from that of the $0 \mathrm{mg} / \mathrm{kg}$ AA without DSS group (unpaired $t$ test): ${ }^{\star} P=0.024,{ }^{\star \star} P=0.018,{ }^{* \star *} P=0.0003,{ }^{\star \star * \star} P<0.0001$. $†$ Mean value was significantly different from that of the $0 \mathrm{mg} / \mathrm{kg}$ AA with DSS group $(P<0.05$; Dunnett's test). 
Table 3. Blood biochemistry of the rats orally administered arachidonic acid (AA) for 8 weeks

(Mean values with their standard errors; ten animals)

\begin{tabular}{|c|c|c|c|c|c|c|c|c|c|c|c|c|c|c|c|c|c|c|c|c|}
\hline \multirow[b]{2}{*}{ Group } & \multicolumn{2}{|c|}{$\mathrm{TP}(\mathrm{g} / \mathrm{l})$} & \multicolumn{2}{|c|}{ ALB $(g / l)$} & \multicolumn{2}{|c|}{$A / G$} & \multicolumn{2}{|c|}{ Glu (mmol/l) } & \multicolumn{2}{|c|}{$\mathrm{TC}(\mathrm{mmol} / \mathrm{l})$} & \multicolumn{2}{|c|}{$\mathrm{TAG}(\mathrm{mmol} / \mathrm{l})$} & \multicolumn{2}{|c|}{$\mathrm{PL}(\mathrm{mg} / \mathrm{l})$} & \multicolumn{2}{|c|}{ NEFA (mEq/l) } & \multicolumn{2}{|c|}{ tBil $(\mu \mathrm{mol} / \mathrm{l})$} & \multicolumn{2}{|c|}{ BUN (mg/l) } \\
\hline & Mean & SE & Mean & SE & Mean & SE & Mean & SE & Mean & SE & Mean & SE & Mean & SE & Mean & SE & Mean & SE & Mean & SE \\
\hline $0 \mathrm{mg} / \mathrm{kg}$ AA with DSS & $50^{\star \star \star \star \star \star *}$ & 1 & $33^{\star \star \star \star \star \star}$ & 1 & $1.95^{\star *}$ & 0.08 & $7 \cdot 4^{\star \star \star \star}$ & 0.3 & $61^{*}$ & 2 & 20 & 6 & 1080 & 70 & 0.88 & 0.17 & 0.51 & 0.00 & $240^{\star \star \star \star \star}$ & 20 \\
\hline $5 \mathrm{mg} / \mathrm{kg}$ AA with DSS & 49 & 1 & 32 & 1 & 1.83 & 0.06 & 7.5 & 0.2 & 57 & 4 & 30 & 6 & 1130 & 90 & 1.02 & 0.11 & 0.51 & 0.00 & 250 & 10 \\
\hline $35 \mathrm{mg} / \mathrm{kg}$ AA with DSS & 51 & 1 & 34 & 1 & 2.01 & 0.05 & $7 \cdot 3$ & 0.3 & 55 & 2 & 29 & 13 & 1050 & 70 & 0.88 & 0.15 & 0.51 & 0.00 & 230 & 10 \\
\hline $240 \mathrm{mg} / \mathrm{kg}$ AA with DSS & 50 & 1 & 32 & 1 & $1 \cdot 76$ & 0.05 & $7 \cdot 7$ & 0.2 & 59 & 2 & 24 & 5 & 1090 & 40 & 1.01 & 0.11 & 0.34 & 0.00 & 230 & 10 \\
\hline $0 \mathrm{mg} / \mathrm{kg} \mathrm{AA}$ without DSS & 57 & 1 & 39 & 0 & $2 \cdot 17$ & 0.06 & 8.5 & 0.2 & 51 & 3 & 49 & 3 & 950 & 30 & 0.56 & 0.03 & 0.51 & 0.00 & 180 & 10 \\
\hline \multirow[t]{2}{*}{$240 \mathrm{mg} / \mathrm{kg}$ AA without DSS } & 55 & 1 & 38 & 0 & $2 \cdot 24$ & 0.05 & $8 \cdot 7$ & 0.4 & 55 & 2 & 47 & 4 & 940 & 20 & 0.43 & 0.06 & 0.51 & 0.00 & 190 & 10 \\
\hline & \multicolumn{2}{|c|}{ Cre $(\mu \mathrm{mol} / \mathrm{l})$} & \multicolumn{2}{|c|}{$\mathrm{IP}(\mathrm{mg} / \mathrm{l})$} & \multicolumn{2}{|c|}{$\operatorname{ALP}(\mathrm{U} / \mathrm{l})$} & \multicolumn{2}{|c|}{ AST (U/l) } & \multicolumn{2}{|c|}{ ALT (U/l) } & \multicolumn{2}{|c|}{ y-GTP (U/I) } & \multicolumn{2}{|c|}{$\mathrm{Ca}(\mathrm{mg} / \mathrm{l})$} & \multicolumn{2}{|c|}{$\mathrm{Na}(\mathrm{mEq} / \mathrm{l})$} & \multicolumn{2}{|c|}{$\mathrm{K}(\mathrm{mEq} / \mathrm{l})$} & \multicolumn{2}{|c|}{$\mathrm{Cl}(\mathrm{mEq} / \mathrm{l})$} \\
\hline Group & Mean & $\mathrm{SE}$ & Mean & SE & Mean & SE & Mean & SE & Mean & SE & Mean & SE & Mean & $\mathrm{SE}$ & Mean & SE & Mean & SE & Mean & SE \\
\hline $0 \mathrm{mg} / \mathrm{kg} \mathrm{AA}$ & $44 \cdot 2$ & 0.0 & 66 & 2 & 444 & 21 & 71 & 8 & 48 & 5 & 1 & 0 & 94 & 1 & 141.9 & 0.5 & $5 \cdot 22^{* * *}$ & 0.51 & $105 \cdot 9$ & 0.5 \\
\hline $5 \mathrm{mg} / \mathrm{kg}$ AA with DSS & 44.2 & 0.0 & 64 & 2 & 481 & 31 & 68 & 7 & 56 & 8 & 2 & 1 & 93 & 1 & 141.5 & 0.3 & 5.62 & 0.36 & $106 \cdot 2$ & 0.6 \\
\hline $35 \mathrm{mg} / \mathrm{kg}$ AA with DSS & $44 \cdot 2$ & 0.0 & 65 & 2 & 487 & 24 & 82 & 16 & 67 & 19 & 1 & 1 & 94 & 1 & 141.5 & 0.5 & 4.98 & 0.44 & $105 \cdot 6$ & 0.6 \\
\hline $240 \mathrm{mg} / \mathrm{kg}$ AA with DSS & 53.0 & 0.0 & 64 & 2 & 453 & 20 & 60 & 5 & 47 & 7 & 1 & 0 & 94 & 1 & 141.4 & 0.3 & $5 \cdot 20$ & 0.36 & $105 \cdot 7$ & 0.5 \\
\hline $0 \mathrm{mg} / \mathrm{kg}$ AA withou & $44 \cdot 2$ & 0.0 & 68 & 1 & 464 & 11 & 65 & 1 & 43 & 2 & 0 & 0 & 95 & 1 & $142 \cdot 5$ & $0 \cdot 1$ & 3.78 & 0.15 & $104 \cdot 8$ & 0.3 \\
\hline $240 \mathrm{mg} / \mathrm{kg}$ AA without DSS & 44.2 & 0.0 & 68 & 2 & 483 & 19 & 69 & 3 & 41 & 2 & 0 & 0 & 93 & 1 & $142 \cdot 8$ & 0.3 & 3.64 & 0.08 & 105.6 & 0.3 \\
\hline
\end{tabular}

TP, total protein; ALB, albumin; A/G, albumin:globulin ratio; Glu, glucose; TC, total cholesterol; PL, phospholipids; tBil, total bilirubin; BUN, blood urea nitrogen; DSS, dextran sodium sulphate; Cre, creatinine; IP, inorganic phosphate;

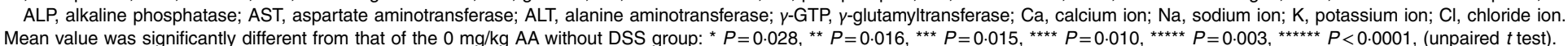


(a)

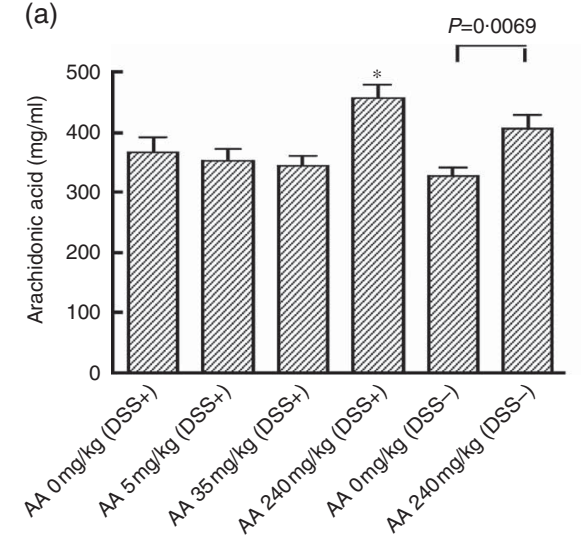

(b)

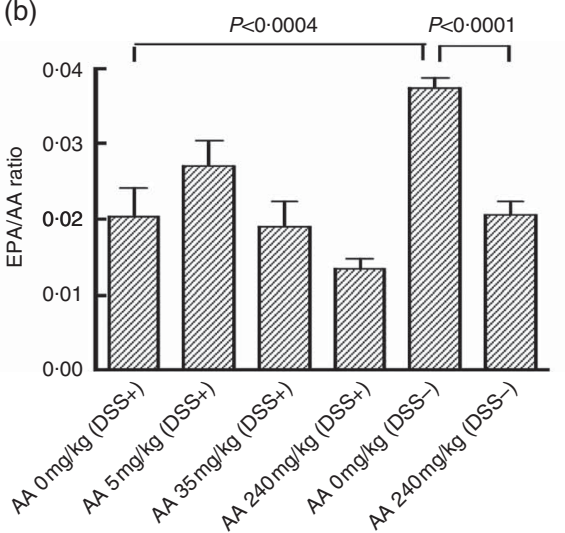

(c)

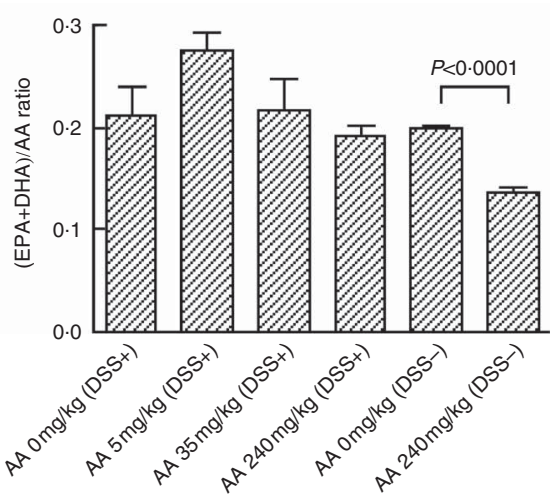

Fig. 1. Plasma arachidonic acid (AA) concentration and EPA:AA and (EPA + DHA):AA ratios in rats given $A A$ for 8 weeks with and without dextran sodium sulphate (DSS) treatment. (a) AA concentration, (b) EPA:AA ratio, (c) (EPA + DHA):AA ratio. Values are means, with their standard errors represented by vertical bars. * Mean value was significantly different from the values in the $0 \mathrm{mg} / \mathrm{kg}$ AA with DSS group $(P<0.05$; Dunnett's test). $P=0.0069$ (a), $P<0.0001$ (b and $\mathrm{c})$, significantly different from the values in the $0 \mathrm{mg} / \mathrm{kg}$ AA without DSS group (unpaired $t$ test). DSS +, with DSS treatment; DSS-, without DSS treatment.

In each group with DSS treatment, a pale liver (five to eight animals per group) and an enlarged spleen (three to seven animals per group) were observed, although the incidence of these findings did not differ between the groups. In addition, a dark reddish caecum was observed in the 0, 5, 35 and $240 \mathrm{mg} / \mathrm{kg}$ AA groups (one, seven, two and six animals, respectively). In the groups without DSS treatment, there were no abnormal findings.

\section{Colon weights}

Mean relative colon weights in the $0,5,35$ and $240 \mathrm{mg} / \mathrm{kg} \mathrm{AA}$ with DSS groups were similar: $123 \cdot 1$ (SE 5.8), 118.0 (SE 7.6), 124.9 (sE 6.7) and $123.2(\mathrm{sE} 4.3) \mathrm{mg} / \mathrm{cm}$, respectively. The relative colon weight in the $0 \mathrm{mg} / \mathrm{kg} \mathrm{AA}$ with DSS group, 91.1 (sE 3.5$) \mathrm{mg} / \mathrm{cm}$ ( $P=0 \cdot 0002$ ), was significantly higher compared with the $0 \mathrm{mg} / \mathrm{kg}$ AA without DSS group and was comparable with that of the $240 \mathrm{mg} / \mathrm{kg}$ AA without DSS group - $92 \cdot 6$ (sE 2.7) $\mathrm{mg} / \mathrm{cm}$.

\section{Microscopic findings}

Hepatic extramedullary haematopoiesis was observed in the groups with DSS treatment, although the incidence was similar in all the groups. Haemorrhage in the submucosal tissues and erosion or ulceration in the epithelium were also observed in the colons of all the animals treated with DSS, and the grade and incidence were similar. Oedema in the colonic submucosae occurred more often in the $240 \mathrm{mg} / \mathrm{kg}$ AA with DSS group than in the $0 \mathrm{mg} / \mathrm{kg} \mathrm{AA}$ with DSS group $(P<0.05)$. The numbers of oedema-positive animals were seven and four, respectively. Infiltration of inflammatory cells in the colonic and caecal tissues of the $240 \mathrm{mg} / \mathrm{kg}$ AA with DSS group appeared more marked compared with the $0 \mathrm{mg} / \mathrm{kg}$ AA with DSS group. There were no inflammatory findings in the organs including the colonic and caecal tissues in either the 0 or $240 \mathrm{mg} / \mathrm{kg} \mathrm{AA}$ without DSS groups.

\section{CD68-positive cells in the colonic mucosa}

As abnormal findings in the caecum and colon were observed only in the $240 \mathrm{mg} / \mathrm{kg}$ AA with DSS group, immunohistochemical staining for CD68-positive cells was performed in the 0 and $240 \mathrm{mg} / \mathrm{kg}$ AA with DSS groups. In the caecum, CD68-positive cells were increased in the $240 \mathrm{mg} / \mathrm{kg}$ AA with DSS group (Fig. 2(a) and (c), $P=0.008$ ). In the colon, although CD68-positive cells tended to be higher in the $240 \mathrm{mg} / \mathrm{kg}$ AA with DSS group (893 (sE 110) cells $/ \mathrm{mm}^{2}$ mucous membrane) compared with the $0 \mathrm{mg} / \mathrm{kg}$ AA with DSS group (730 (sE 75) cells $/ \mathrm{mm}^{2}$ mucous membrane), this difference was NS (Fig. 2(b) and (d)).

\section{Ulcerated area}

The Alcian blue-stained areas of the mucosa in the 0, 5, 35 and $240 \mathrm{mg} / \mathrm{kg}$ AA with DSS groups were 0.82 (SE 0.27), 0.74 (SE 0.14 ), 1.42 (SE 0.42) and 1.62 (sE 0.52) \%, respectively (Fig. 3). These areas were found to be increased compared with those in the 0 and $240 \mathrm{mg} / \mathrm{kg} \mathrm{AA}$ without DSS groups, $0 \cdot 41$ (SE 0.11) and 0.20 (sE 0.03$) \%$, respectively. There were no significant differences within the groups treated with DSS or within the groups without DSS treatment.

\section{Myeloperoxidase activity in colon tissue}

In the DSS-treated groups, AA intake dose-dependently increased MPO activity in the colonic tissues ( $r^{2}$ 0.9999). MPO activity in the $240 \mathrm{mg} / \mathrm{kg}$ AA group, $4 \cdot 10$ (sE $0 \cdot 2$ ) mU/mg protein, was significantly higher than that in the $0 \mathrm{mg} / \mathrm{kg}$ AA group, $2 \cdot 70(\mathrm{se} 0 \cdot 3) \mathrm{mU} / \mathrm{mg}$ protein $(P<0 \cdot 01$, Fig. 4). The activities in the 0 and $240 \mathrm{mg} / \mathrm{kg} \mathrm{AA}$ without DSS groups were low (0.54 (sE $0.2)$ and $0.92(\mathrm{SE} 0.2) \mathrm{mU} / \mathrm{mg}$ protein, respectively). The activity in the $0 \mathrm{mg} / \mathrm{kg}$ AA with DSS group was higher compared with the $0 \mathrm{mg} / \mathrm{kg}$ AA without DSS group $(P<0 \cdot 0001)$. 
(a)

AA $0 \mathrm{mg} / \mathrm{kg}$

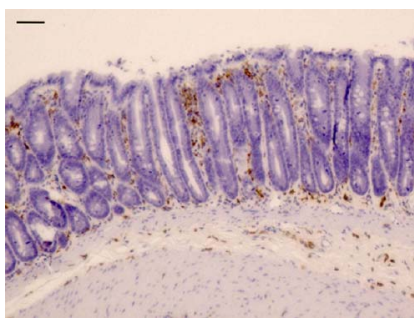

AA $240 \mathrm{mg} / \mathrm{kg}$

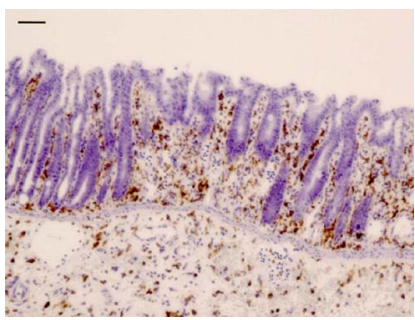

(c)

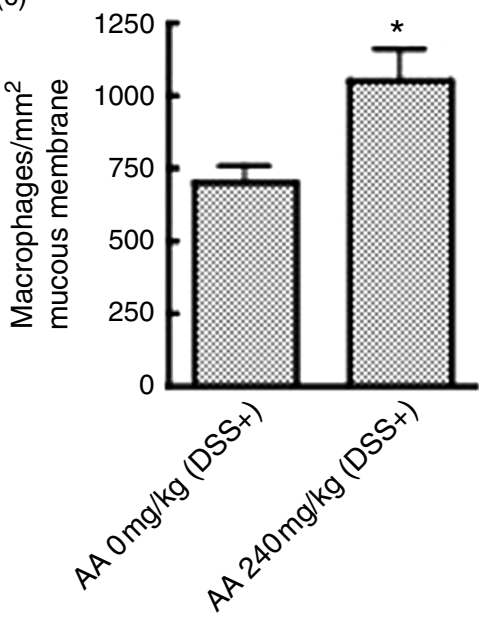

(b)

AA $0 \mathrm{mg} / \mathrm{kg}$

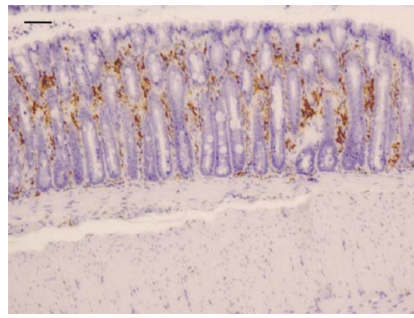

AA $240 \mathrm{mg} / \mathrm{kg}$

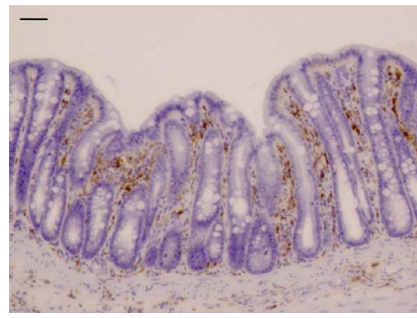

(d)

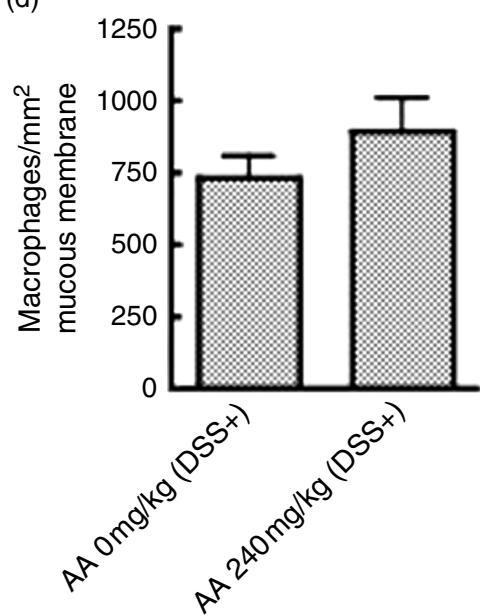

Fig. 2. CD68 expression of the caecum ( $a$ and $c$ ) and colonic ( $b$ and d) tissues in rats given arachidonic acid (AA) at 0 and $240 \mathrm{mg} / \mathrm{kg}$ with dextran sodium sulphate (DSS) treatment. ( $a$ and b) Typical photographs of immunohistochemistry for CD68. (c and d) Number of CD68-positive cells (macrophages) in the tissues (cells/mm ${ }^{2}$ mucous membrane). Scale bar, $50 \mu \mathrm{m}$. $n 10$. Values are means, with their standard errors represented by vertical bars. ${ }^{*}$ Mean value was significantly different from the values in the $0 \mathrm{mg} / \mathrm{kg} \mathrm{AA}$ with DSS group $(P=0.008$; unpaired $t$ test).

\section{Cyclo-oxygenase-2 in homogenised colon tissue}

In the DSS-treated groups, COX-2 levels in the colonic tissues were increased by AA in a dose-dependent manner $\left(r^{2} 0 \cdot 9407\right)$. The COX-2 concentration in the $240 \mathrm{mg} / \mathrm{kg}$ AA group, 0.67 (sE 0.03 ) $\mathrm{ng} / \mathrm{mg}$ protein, was higher compared with the $0 \mathrm{mg} / \mathrm{kg}$ AA group, 0.42 (sE 0.03$) \mathrm{ng} / \mathrm{mg}$ protein $(P<0.05$, Fig. 5). COX-2 level in the $0 \mathrm{mg} / \mathrm{kg}$ AA with DSS group was higher compared with the $0 \mathrm{mg} / \mathrm{kg}$ AA without DSS group, 0.05 (SE 0.02 ) ng/mg protein $(P<0 \cdot 0001)$. There were no differences in concentrations between the groups without DSS treatment.

\section{Eicosanoids in the culture media of the colonic mucosa}

In the DSS-treated groups, the concentration of $\mathrm{TXB}_{2}$ was dose-dependently increased by AA $\left(r^{2}\right.$ 0.9990) and was significantly higher in the 35 and $240 \mathrm{mg} / \mathrm{kg}$ AA groups than in the $0 \mathrm{mg} / \mathrm{kg} \mathrm{AA}$ group $(P<0.05$ and 0.01 , respectively, Fig. 6(a)). The concentrations of 6-keto $\mathrm{PGF}_{1 \alpha}$ in the 5 and $240 \mathrm{mg} / \mathrm{kg}$ AA groups were lower compared with the $0 \mathrm{mg} / \mathrm{kg}$ AA group $(P<0.05$, Fig. $6(\mathrm{~b}))$. The concentrations of $\mathrm{PGE}_{2}$ in the 5,35 and $240 \mathrm{mg} / \mathrm{kg}$ AA groups tended to be higher compared with the $0 \mathrm{mg} / \mathrm{kg} \mathrm{AA}$ group (Fig. 6(c)). The concentrations of $\mathrm{LTB}_{4}$ in the 5,35 and $240 \mathrm{mg} / \mathrm{kg}$ AA groups were higher compared with the $0 \mathrm{mg} / \mathrm{kg}$ AA group $(P<0.05$ or 0.01 , Fig. $6(\mathrm{~d})$ ), although the increase was not dose-dependent. The concentrations of 6-keto $\mathrm{PGF}_{1 \alpha}$ and $\mathrm{PGE}_{2}$ in the $0 \mathrm{mg} / \mathrm{kg}$ AA with DSS group were higher compared with the $0 \mathrm{mg} / \mathrm{kg}$ AA without DSS group $\left(P=0.0003\right.$ and 0.0038 , respectively), whereas $\mathrm{TXB}_{2}$ and $\mathrm{LTB}_{4}$ concentrations were not different. There were no significant differences in the concentrations of these four eicosanoids between the 0 and the $240 \mathrm{mg} / \mathrm{kg}$ AA without DSS groups. 


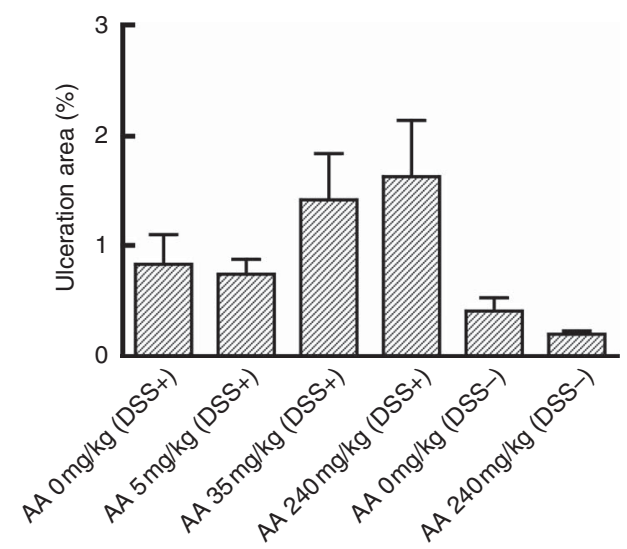

Fig. 3. Ulcerated area in the colon of rats given arachidonic acid (AA) for 8 weeks with and without dextran sodium sulphate (DSS) treatment. Isolated colon (approximately $4 \mathrm{~cm}$ ) was opened along its long axis and stained with $1 \%$ Alcian blue solution. The ratio of stained areas to unstained areas of the colonic mucosa was calculated. Values are means, with their standard errors represented by vertical bars. DSS +, with DSS treatment; DSS-, without DSS treatment.

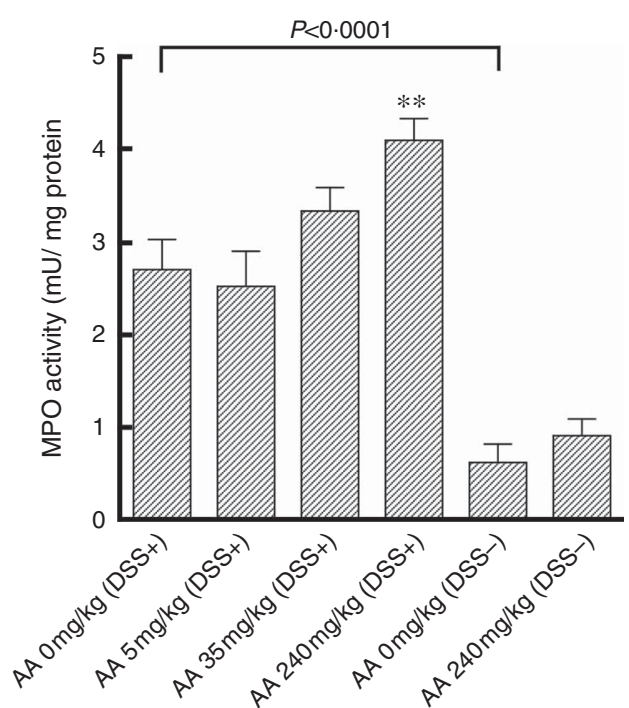

Fig. 4. Myeloperoxidase (MPO) activities in the colon of rats orally administered arachidonic acid (AA) for 8 weeks with and without dextran sodium sulphate (DSS) treatment. Values are means, with their standard errors represented by vertical bars. ${ }^{*}$ Mean value was significantly different from the values in the $0 \mathrm{mg} / \mathrm{kg}$ AA with DSS group $(P<0.01$; Dunnett's test). †Significantly different from the values in the $0 \mathrm{mg} / \mathrm{kg}$ AA without DSS group $(P<0.0001$; unpaired $t$ test). DSS +, with DSS treatment; DSS-, without DSS treatment.

\section{Discussion}

In the present study, red-stained faeces, body weight loss and decreases in erythrocytes, HCT and Hb were observed only in the DSS-treated groups. Increased MPO activity, which was reported in rats with DSS-induced colitis ${ }^{(17)}$, was also found in the DSS-treated animals. Thus, it was confirmed that the DSS treatment adopted in the present study effectively caused colitis. However, there were no significant changes by AA in the DSS-induced decrease in body weight or increase in relative

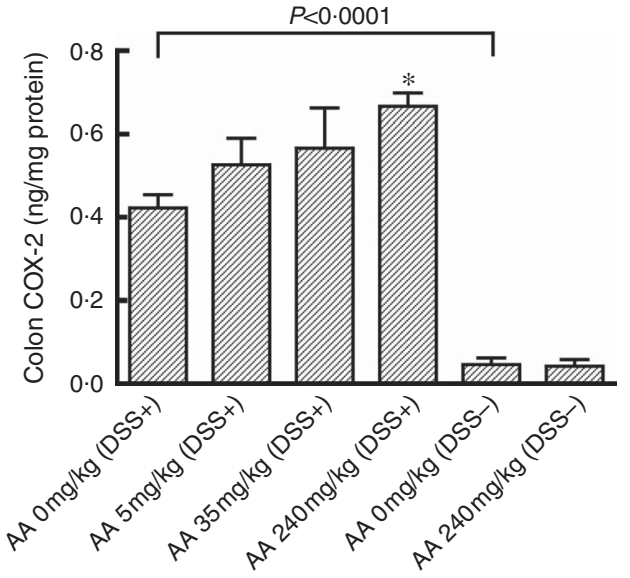

Fig. 5. Cyclo-oxygenase-2 (COX-2) concentration in the colon of rats orally administered arachidonic acid (AA) for 8 weeks with and without dextran sodium sulphate (DSS) treatment. Values are means, with their standard errors represented by vertical bars. *Mean value was significantly different from the values in the $0 \mathrm{mg} / \mathrm{kg}$ AA with DSS group $(P<0.05$; Dunnett's test). †Significantly different from the values in the $0 \mathrm{mg} / \mathrm{kg}$ AA without DSS group $(P<0.0001$; unpaired $t$ test). DSS + , with DSS treatment; DSS-, without DSS treatment.

colon weight. In these animals, the grades of loose stools, diarrhoea and red-stained faeces were also comparable. However, MPO and COX-2 in the colitic tissue and $\mathrm{TXB}_{2}$, 6-keto $\mathrm{PGF}_{1 \alpha}$ and $\mathrm{PGE}_{2}$ in the cultured mucosa were found to be increased by AA administration. Moreover, macrophage infiltration in the colonic mucosa was also confirmed in the $240 \mathrm{mg} / \mathrm{kg} \mathrm{AA}$ with DSS group. Thus, AA is considered to have proinflammatory effects on DSS-induced colitis.

In the $240 \mathrm{mg} / \mathrm{kg}$ AA without DSS group, plasma levels of AA was significantly higher compared with the $0 \mathrm{mg} / \mathrm{kg}$ AA without DSS group, and EPA:AA and (EPA+DHA):AA ratios were reduced to approximately 50 and $70 \%$ of those in the $0 \mathrm{mg} / \mathrm{kg}$ AA without DSS group, respectively. Such a reduction could be due to an increased level of plasma AA. In patients with ulcerative colitis, AA level was elevated in the colonic mucosa $^{(18)}$, and high AA and low EPA levels were found in inflamed colonic mucosa ${ }^{(19)}$. In addition, the $n-6$ PUFA synthetic pathway was found to be up-regulated in colitis ${ }^{(19)}$. It has also been reported that patients with inflammatory bowel disease possibly utilised more AA than healthy subjects because the AA ratio in plasma NEFA was lower in those patients ${ }^{(20)}$. As a decreased EPA:AA ratio is one of the indicators for inflammatory diseases, the relatively lower EPA:AA ratio in the $240 \mathrm{mg} / \mathrm{kg}$ AA with DSS group may be an unfavourable condition, at least for the prevention of inflammatory diseases.

$\mathrm{PGE}_{2}$ and 6-keto $\mathrm{PGF}_{1 \alpha}$ concentrations in the culture media of colonic mucosa of the AA at $0 \mathrm{mg} / \mathrm{kg}$ per d with DSS treatment group were significantly increased compared with the AA at $0 \mathrm{mg} / \mathrm{kg}$ per $\mathrm{d}$ without DSS treatment group. However, neither $\mathrm{TXB}_{2}$ nor $\mathrm{LTB}_{4}$ concentrations changed in these animals. Thus, at least under the present experimental conditions, DSS treatment appears to affect the syntheses of specific eicosanoids.

In the DSS-treated groups, a dose-dependent increase by AA of $\mathrm{TXB}_{2}$ was found in the culture media of colonic mucosa from 
(a)

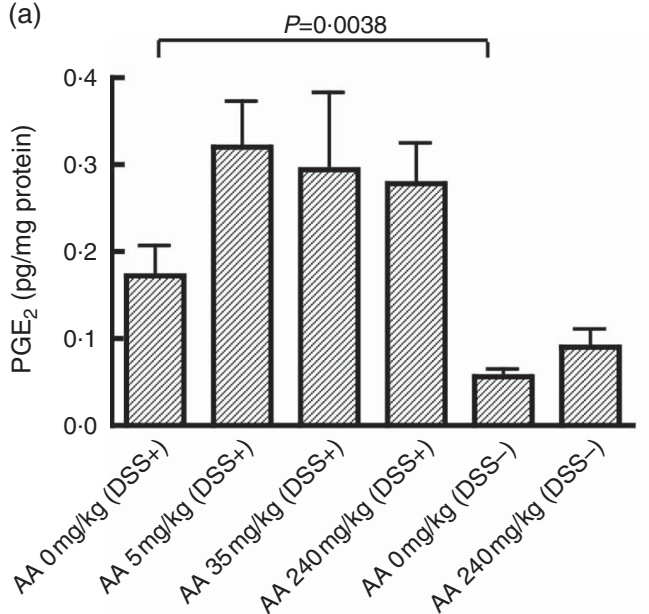

(c)
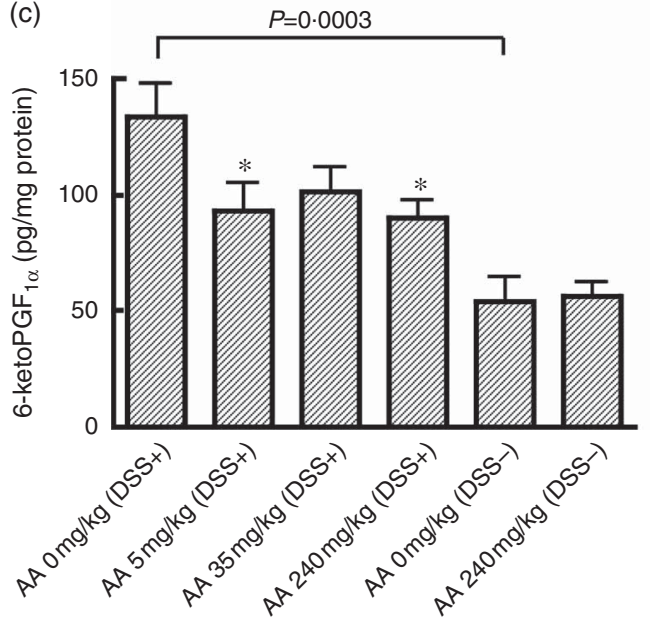

(b)

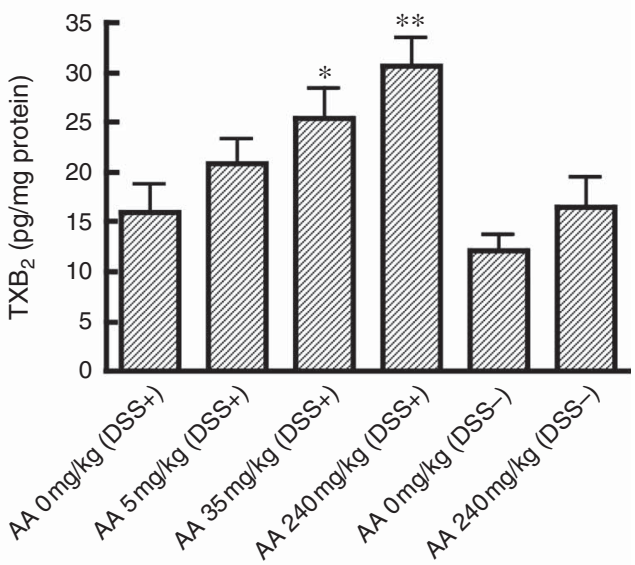

(d)

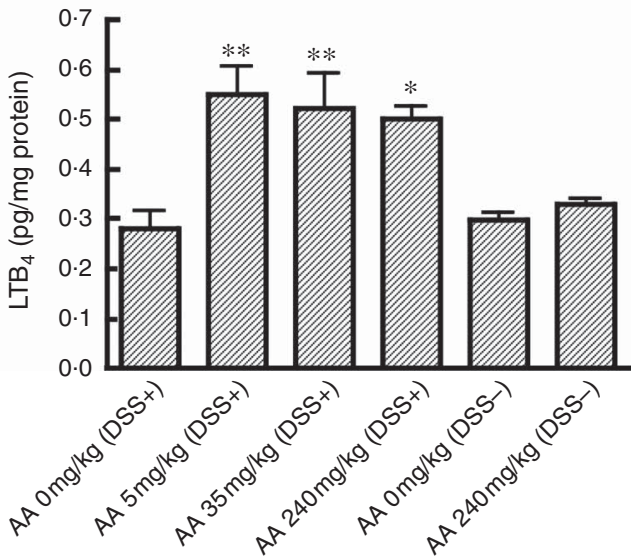

Fig. 6. Eicosanoids in culture media of the colonic mucosa of rats orally administered arachidonic acid (AA) for 8 weeks with and without dextran sodium sulphate (DSS) treatment. (a) Thromboxane $\mathrm{B}_{2}\left(\mathrm{TXB}_{2}\right)$, (b) 6-keto prostaglandin $\mathrm{F}_{1 a}$ (6-keto PGF $\left.\mathrm{F}_{1 a}\right)$, (c) prostaglandin $\mathrm{E}_{2}\left(\mathrm{PGE}_{2}\right)$, (d) leukotriene $\mathrm{B}_{4}\left(\mathrm{LTB}_{4}\right)$. Values are means, with their standard errors represented by vertical bars. Mean value was significantly different from that of the $0 \mathrm{mg} / \mathrm{kg}$ AA with $D S S$ group: ${ }^{*} P<0.05,{ }^{* *} P<0.01$ (Dunnett's test). $P=0.0003$ (b), $P=0.0038$ (c), significantly different from the values in the $0 \mathrm{mg} / \mathrm{kg}$ AA without DSS group (unpaired $t$ test). DSS + , with DSS treatment; and DSS-, without DSS treatment.

the rats given $\mathrm{AA}$ at $0-240 \mathrm{mg} / \mathrm{kg}$ per $\mathrm{d}$. The increase in $\mathrm{TXB}_{2}$ was significant in the AA at 35 and $240 \mathrm{mg} / \mathrm{kg}$ per d groups compared with the $\mathrm{AA}$ at $0 \mathrm{mg} / \mathrm{kg}$ per $\mathrm{d}$ group. $\mathrm{PGE}_{2}$ in the culture media tended to increase in the groups given $\mathrm{AA}$ at 5,35 and $240 \mathrm{mg} / \mathrm{kg}$ per d compared with the AA at $0 \mathrm{mg} / \mathrm{kg}$ per $\mathrm{d}$ group. Furthermore, $\mathrm{LTB}_{4}$ concentration in the AA at 5, 35 and $240 \mathrm{mg} / \mathrm{kg}$ per d groups was significantly higher compared with the $\mathrm{AA}$ at $0 \mathrm{mg} / \mathrm{kg}$ per $\mathrm{d}$ group, although this change was not dose-dependent. These results demonstrate that AA increases $\mathrm{TXB}_{2}, \mathrm{PGE}_{2}$ and $\mathrm{LTB}_{4}$ concentrations in colitic mucosa of DSS-treated rats. The increases in these eicosanoids occurred at $5 \mathrm{mg} / \mathrm{kg}$ per $\mathrm{d}$ and appeared to be saturated, except for $\mathrm{TXB}_{2}$, which showed a dose-dependent increase. However, 6-keto $\mathrm{PGF}_{1 \alpha}$ concentration in the culture media in the AA at 5 and $240 \mathrm{mg} / \mathrm{kg}$ per d groups was significantly lower compared with the AA at $0 \mathrm{mg} / \mathrm{kg}$ per d group. Although the reason for such a decrease is not clear, it should be noted that AA-induced changes in the levels of eicosanoids, including the decrease in 6-keto $\mathrm{PGF}_{1 \alpha}$, led to the facilitation of an underlying inflammation, and the effects appear even at $5 \mathrm{mg} / \mathrm{kg}$ per $\mathrm{d}$. In contrast, in the rats without DSS treatment, no significant differences in these four eicosanoids were observed between the AA at 0 and 240 groups, suggesting the lack of proinflammatory effects of AA in rats without an underlying inflammation.

Lipoxin $\mathrm{A}_{4}$, resolvin $\mathrm{E}_{1}$ and Maresin 1 are PUFA-derived mediators that have anti-inflammatory effects in experimental models of colitis ${ }^{(21,22)}$. It has been shown in patients with inflammatory bowel disease ${ }^{(23)}$ and in mice with DSS-induced colitis $^{(24)}$ that there is a relationship between PUFA and enterobacterial flora in the bowel, which is affected by inflammation. Thus, although not examined in the present study, investigations regarding the role of these mediators in inflammatory diseases and the influence of enterobacterial flora in relation to AA intake are necessary.

On macroscopic observation, a dark red colouration was observed in the colons of animals in the DSS-treated groups. 
Although the effect was not dose-dependent, the DSS-induced mucosal oedema in the colon was aggravated by AA at $240 \mathrm{mg} / \mathrm{kg}$ and was accompanied by an increased local macrophage infiltration. This increase was significant in the caecum. As the expressions of IL- $1 \beta$, IL- 6 , TNF $\alpha$ and IL- 17 were reported in macrophages from patients with colitis ${ }^{(25-28)}$, the involvement of such inflammatory cytokines in the exacerbation of DSS-induced colitis by AA in rats remains to be elucidated.

Both MPO activity and COX-2 concentration in the colonic tissue were markedly increased by DSS treatment and were facilitated by AA in a dose-dependent manner, suggesting an aggravation by AA of DSS-induced colitis. The Alcian bluestained ulcerated area tended to be increased by AA, although this was not statistically significant. A higher dose of AA than $240 \mathrm{mg} / \mathrm{kg}$ per $\mathrm{d}$ may lead to further progression of ulceration or deterioration of the bowel disease in rats, as the tendency of the increase in the ulceration was dose-dependent and not saturated, even at $240 \mathrm{mg} / \mathrm{kg}$ per d. In addition, AA may change the differential leucocyte count, as the lymphocyte ratio, which increases in chronic inflammatory conditions, was elevated in the AA at $240 \mathrm{mg} / \mathrm{kg}$ with DSS-induced colitis group. However, MPO activity in the $240 \mathrm{mg} / \mathrm{kg}$ AA without DSS group was not different from that in the $0 \mathrm{mg} / \mathrm{kg}$ AA without DSS group. This finding demonstrates that AA does not induce inflammation or colitis in a normal colon.

In the present study, the groups of rats were configured not only for examining AA effects on DSS-induced colitis but also for a safety evaluation of AA. In the $240 \mathrm{mg} / \mathrm{kg}$ per d AA without DSS group, every parameter examined was comparable with that of the $0 \mathrm{mg} / \mathrm{kg}$ per $\mathrm{d}$ AA without DSS group, except for increased plasma AA level, indicating that AA at $240 \mathrm{mg} / \mathrm{kg}$ per $\mathrm{d}$, roughly fifty times the dose in a previous study ${ }^{(15)}$, has no adverse effects in rats without DSS-induced colitis.

In summary, the 8-week repeated administration of AA at 5, 35 and $240 \mathrm{mg} / \mathrm{kg}$ per $\mathrm{d}$ had almost no effects in rats without DSS-induced colitis. However, in rats with DSS-induced colitis, $\mathrm{AA}$ at $240 \mathrm{mg} / \mathrm{kg}$ exacerbated the inflammation. Moreover, AA-induced increases in the production of $\mathrm{PGE}_{2}$ and $\mathrm{LTB}_{4}$ and a decrease of $\mathrm{PGI}_{2}$ were found in the culture media of colonic mucosae from rats with DSS-induced colitis, and these changes appeared saturated at $5 \mathrm{mg} / \mathrm{kg}$ per $\mathrm{d}$.

Thus, it can be concluded that AA intake possibly enhances an underlying inflammation and an excessive intake may aggravate inflammatory diseases, although AA appears to be safe for those in a healthy condition.

\section{Acknowledgements}

This work was supported in part by the Programme for the Health and Labour Sciences Research Grants, Japan (H22-foodgeneral-002, H24-food-general-004), and the Grant-in-Aid for Scientific Research (C), Japan (24501030, 26350133).

The authors' contributions are as follows: Y. N. designed the study; Y. N. and N. O. wrote the manuscript; Y. N., X. J., S. T., S. A. and N. I. performed the animal experiments and the data analyses; M. F. and Y. T. performed the biochemical and haematological examinations; D. M., A. H. and T. M. performed the analysis of fatty acids; and Y. N., X. J. and T. N. performed the pathological examinations. All the authors were responsible for the final manuscript.

The authors would like to thank Mr David L. Carleton for his help in correcting the English.

The authors declare no conflicts of interest.

\section{Supplementary Material}

For supplementary material/s referred to in this article, please visit http://dx.doi.org/10.1017/S000711451500224X.

\section{References}

1. Söderberg M, Edlund C, Kristensson K, et al. (1991) Fatty acid composition of brain phospholipids in aging and in Alzheimer's disease. Lipids 26, 421-425.

2. McGahon B, Clements MP \& Lynch MA (1997) The ability of aged rats to sustain long-term potentiation is restored when the age-related decrease in membrane arachidonic acid concentration is reversed. Neuroscience 81, 9-16.

3. Kotani S, Sakaguchi E, Warashina S, et al. (2006) Dietary supplementation of arachidonic and docosahexaenoic acids improves cognitive dysfunction. Neurosci Res 56, 159-164.

4. Ishikura Y, Ikeda G, Akimoto K, et al. (2009) Arachidonic acid supplementation decreases P300 latency and increases P300 amplitude of event-related potentials in healthy elderly men. Neuropsychobiology 60, 73-79.

5. Tokuda H, Kontani M, Kawashima H, et al. (2014) Arachidonic acid-enriched triacylglycerol improves cognitive function in elderly with low serum levels of arachidonic acid. J Oleo Sci $\mathbf{6 3}$, 219-227.

6. Kiso Y (2011) Pharmacology in health foods: effects of arachidonic acid and docosahexaenoic acid on the age-related decline in brain and cardiovascular system function.J Pharmacol Sci 115, 471-475.

7. Innis SM (2003) Perinatal biochemistry and physiology of long-chain polyunsaturated fatty acids. J Pediatr 143, S1-S8.

8. Koletzko B, Lien E, Agostoni C, et al. (2008) The roles of longchain polyunsaturated fatty acids in pregnancy, lactation and infancy: review of current knowledge and consensus recommendations. J Perinat Med 36, 5-14.

9. Hoffman DR, Boettcher JA \& Diersen-Schade DA (2009) Toward optimizing vision and cognition in term infants by dietary docosahexaenoic and arachidonic acid supplementation: a review of randomized controlled trials. Prostaglandins Leukot Essent Fatty Acids 81, 151-158.

10. Codex Alimentarius Commission (1981) Standard for infant formula and formulas for special medical purposes intended for infants. CODEX STAN 72-1981, Amendment, April 2011. http:// www.codexalimentarius.org (accessed September 2014).

11. Cooper HS, Murthy SNS, Shah RS, et al. (1993) Clinicopathologic study of dextran sulfate sodium experimental murine colitis. Lab Invest 69, 238-249.

12. Gaudio E, Taddei G, Vetuschi A, et al. (1999) Dextran sulfate sodium (DSS) colitis in rats. Dig Dis Sci 44, 1458-1475.

13. Ramarkers JD, Mensink RP, Verstege MI, et al. (2008) An arachidonic acid-enriched diet does not result in more colonic inflammation as compared with fish oil- or oleic acidenriched diets in mice with experimental colitis. BrJ Nutr 100, 347-354.

14. Tateishi N, Kakutani S, Kawashima H, et al. (2014) Dietary supplementation of arachidonic acid increases arachidonic 
acid and lipoxin $\mathrm{A}_{4}$ contents in colon, but does not affect severity or prostaglandin $\mathrm{E}_{2}$ content in murine colitis model. Lipids Health Dis 13, 30.

15. Kakutani S, Ishikura Y, Tateishi N, et al. (2011) Supplementation of arachidonic acid-enriched oil increases arachidonic acid contents in plasma phospholipids, but does not increase their metabolites and clinical parameters in Japanese healthy elderly individuals: a randomized controlled study. Lipids Health Dis 10, 241.

16. Bligh EG \& Dyer WJ (1959) A rapid method of total lipid extraction and purification. Can J Biochem Physiol 37, 911-917.

17. de Oliveira LG, da Cunha AL, Duarte AC, et al. (2014) Positive correlation between disease activity index and matrix metalloproteinase activity in a rat model of colitis. Arq Gastroenterol 51, 107-112.

18. Pacheco S, Hillier K \& Smith C (1987) Increased arachidonic acid levels in phospholipids of human colonic mucosa in inflammatory bowel disease. Clin Sci 73, 361-364.

19. Pearl DS, Masoodi M, Eiden M, et al. (2014) Altered colonic mucosal availability of $n-3$ and $n-6$ polyunsaturated fatty acids in ulcerative colitis and the relationship to disease activity. J Crohns Colitis 8, 70-79.

20. Figler M, Gasztonyi B, Cseh J, et al. (2007) Association of $n-3$ and $n$-6 long-chain polyunsaturated fatty acids in plasma lipid classes with inflammatory bowel diseases. Br J Nutr 97, 1154-1161.

21. Weylandt KH, Kang JX, Wiedenmann B, et al. (2007) Lipoxins and resolvins in inflammatory bowel disease. Inflamm Bowel Dis 13, 797-799.
22. Marcon R, Bento AF, Dutra RC, et al. (2013) Maresin 1, a proresolving lipid mediator derived from omega-3 polyunsaturated fatty acids, exerts protective actions in murine models of colitis. J Immunol 191, 4288-4298.

23. Frank DN, St Amand AL, Feldman RA, et al. (2007) Molecular-phylogenetic characterization of microbial community imbalances in human inflammatory bowel diseases. Proc Natl Acad Sci USA 104, 13780-13785.

24. Nagalingam NA, Kao JY \& Young VB (2011) Microbial ecology of the murine gut associated with the development of dextran sodium sulfate-induced colitis. Inflamm Bowel Dis 17, 917-926.

25. Woywodt A, Ludwig D, Neustock P, et al. (1999) Mucosal cytokine expression, cellular markers and adhesion molecules in inflammatory bowel disease. Eur J Gastroenterol Hepatol 11, 267-276.

26. Fujino S, Andoh A, Bamba S, et al. (2003) Increased expression of interleukin 17 in inflammatory bowel disease. Gut 52, 65-70.

27. Nielsen OH, Kirman I, Rüdiger N, et al. (2003) Upregulation of interleukin-12 and -17 in active inflammatory bowel disease. Scand J Gastroenterol 38, 180-185.

28. Caprioli F, Bosè F, Rossi RL, et al. (2013) Reduction of CD68 + macrophages and decreased IL-17 expression in intestinal mucosa of patients with inflammatory bowel disease strongly correlate with endoscopic response and mucosal healing following infliximab therapy. Inflamm Bowel Dis 19, 729-739. 